ICHEU 2021

International Conference «Humanity in the Era of Uncertainty»

\title{
PRACTICAL SKILLS DEVELOPMENT OF AUTOMOTIVE ENGINEERS IN TIME OF THE COVID-19 PANDEMIC
}

\author{
Ekaterina I. Makarenko (a), Larisa G. Petrova (b)*, Aleksandr N. Solovyev (c), \\ Sergey L. Abrakov (d) \\ *Corresponding author
}

(a) Moscow Automobile and Road Construction State Technical University (MADI), 64, Leningradsky Prospekt, Moscow 125319, Russia

(b) Moscow Automobile and Road Construction State Technical University (MADI), 64, Leningradsky Prospekt, Moscow 125319, Russia, petrova_madi@mail.ru

(c) Moscow Automobile and Road Construction State Technical University (MADI), 64, Leningradsky Prospekt, Moscow 125319, Russia

(d) Moscow Automobile and Road Construction State Technical University (MADI), 64, Leningradsky Prospekt, Moscow 125319, Russia

\begin{abstract}
The introduction of lockdown due to the spread of COVID-19 in the spring of 2020 has fundamentally changed the way people live around the world. We had to solve the problems that have arisen in families, the education system, the economy and finance. The higher education authorities faced the issues of organizing distance education for students. The work analyzes the opinions expressed by full-time MADI students who had to switch to distance learning in March 2020. The authors have classified the students' answers. In general, the students' attitude to distance learning is negative. Especially it applies to practical training. Among the main drawbacks are technical difficulties, household and economic problems, the lack of quality methodical study by teachers. The results of the content analysis of the opinions of MADI students in general coincide with the results of processing a mass survey of students of different universities. Further analysis of the problems of distance learning is certainly necessary.
\end{abstract}

2357-1330 @ 2021 Published by European Publisher.

Keywords: COVID-19, distance learning, technical university, sociological survey 


\section{Introduction}

The introduction of quarantine measures (anti-epidemic measures) in connection with the spread of COVID-19 in the spring of 2020 has fundamentally changed the way people live around the world. We had to solve the problems that have arisen in families, the education system, the economy and finance. Despite the fact that the problems of distance learning are discussed in professional literature for more than two decades, in parallel with the development of the Internet, in practice the system of higher education in Russia was not ready enough for a sudden transition from full-time education (with elements of distance learning) to remote.

\section{Problem Statement}

The higher education authorities faced the issues of organizing continuous education of students, conducting certification tests. The teaching community had to solve the most complex methodological, organizational and methodical issues, as well as the problems of material support of their classes, conducted in a distance format. For university students, this crisis situation is even more difficult because they faced not only the need to learn new forms of classes and solve the problems of material support for these classes, but also a number of everyday problems (for example, change of residence for people living in a dormitory). The adaptation of students is complicated by the lack of life experience. Namely, today's students are an age cohort that has not faced transformations in our country over the past three decades due to both the transition of the entire Russian society to market relations and the global economic crises of 2008 and 2014. In April-May 2020, a content analysis of 45 student essays on social adaptation was conducted in MADI in order to study the views of MADI students on the problems encountered, and in July, a survey of 86 more students was conducted.

\section{Research Questions}

The undoubted relevance of the study of common problems of transition to distance learning in the Russian higher education system has attracted many researchers. For example, during the sociological survey "Opinions of Russian universities' students on the forced distance learning", conducted in MayJune 2020, 3,423 university students were interviewed in all regions of the Russian Federation (Aleshkovskiy et al., 2020). This work touches upon such global problems of the transition to distance learning as the resources used, the organization of lectures and workshops, assessment of the positive and negative sides of distance learning; prospects, limitations and trajectories of distance learning implementation in Russian higher education institutions. The heads of higher education organizations, professors and students have their own views on these issues. We will focus on the latter community. 


\section{Purpose of the Study}

The aim of the research is to study the attitude of the students to distance learning and analyse the main difficulties they had to face.

\section{Research Methods}

The research was conducted by the content analysis method of 45 student essays on social adaptation (April-May 2020) and then in July 2020 by interviewing participants on a sample population (determined by nesting method in six groups with a total number of 86 students).

The main understanding of social adaptation, types and vectors of activation of actions for more successful passing and completion of studies in modern conditions were defined as the problem field of content analysis. In general, an essay is a text of a small volume and free composition on a specific topic with an attempt to convey their own opinion and position of the authors. Not all of students' works met the requirements of the essay, as they did not reflect the opinion of students themselves, but contained only fragments of material on social adaptation received from the Internet. Such 9 works were "culled". This fact illustrates one of the problems of the modern information space and one of the challenges faced by teachers today. It is necessary to teach students to use information resources competently.

Among the remaining 36 works, 20 presented by students of the Faculty of Design and Mechanical Engineering (KMF - 2nd year) and 16 presented by students of the Faculty of Road Construction (DSF 3rd year) of the Moscow Automobile and Road Construction State Technical University (MADI). These students study in the University five years and after graduation they will be awarded the title of engineer, when enrolled by the competition for these specialties passing score is relatively high.

The survey of students on a sample set was conducted during the training practice of students of the "Automobile transport" faculty. This practice was held at the Department of "Technology of construction materials". In the summer of 2020, the teachers of the Department had to organize this practice in online format. After its completion, the Associate Professor of the Department P.E. Demin conducted a survey of 86 participants. The results of this survey are given below.

We would like to note the peculiarities of the content analysis. First, students' opinions are quoted literally - while their stylistic and spelling mistakes and inaccuracies contained in the essay are preserved. Secondly, based on ethical rules, no specific groups or names of MADI students are indicated.

Our research is indicative: we hope to study trends in the opinions of future engineers at the beginning of the pandemic crisis. It is essential that some students in their essays themselves pointed to the importance of several characteristics of the areas of adaptation in the current environment among those that were identified by the authors of the article and based on which the further presentation of results is structured.

\section{Findings}

As expected, the majority of future engineers in their essays pointed to the problems of studying during the pandemic crisis (22 people). The main emphasis was on distance learning and digital technology development. 
It is well known that the issues of digitalization of education and economics in general were raised even before the announcement of self-isolation and quarantine regimes. For example, the Program "Digital Economy of Russia" was approved by the Government of the Russian Federation on July 28, 2017. One of the articles of the Governmental Decree № 570 from 08.05.2019 reads: "providing by 2024 at least 20 percent of students in higher education programs the opportunity to master individual courses, disciplines (modules), including online courses, using the resources of other organizations engaged in educational activities, including universities, ensuring the compliance of the quality of training of students with international standards". Unfortunately, the reality of life demanded a $100 \%$ transition to online education in 2020 .

The practical implementation of the use of information and communication technologies (ICT) in education, including in the new reality, is described in many monographs and articles (Donskikh, 2020; Gafurov et al., 2020; Guralnik, 2020; Melezhik et al., 2020; Mikhailov \& Denisova, 2020; Morshchilov et al., 2019) which contain an extensive bibliography on this issue. Let us consider the opinions expressed in the essays of students, arranging them in descending order of references in student works.

\subsection{The problems of total (forced) distance learning in a pandemic}

Students explain in their essays the difficulty of mastering a number of subjects in the distance form of the following circumstances.

1) Difficulties in accessing the Internet. Some students explicitly stated: "I have to go out to a field to get Internet signal"; "In this situation I had to leave the city for an indefinite period of time. An internet connection here is like gold and I can't stay on the Internet for a long time". But what is interesting is that almost all the students who pointed to the difficulties were able to adapt somehow. For example, a young man from the Faculty of Design and Mechanical Engineering described this situation: "Everybody left for villages and suburbs of the country (as they recommended). Civilization has not reached yet to these places. And here, in order for everything to continue functioning (students, schoolchildren - studying, who works - working, etc.), the Government decided to introduce distance learning (for employees - respectively). And everything worked out - we continue to learn. (But, they did not take into account the fact that many do not have access to a PC or good Internet!). Bottom line: Everything is good; in this situation we have adapted to the urgent problem and somehow solved it".

2) Many teachers are not ready to work remotely. They have superficial knowledge or are not familiar with many digital platforms and information transfer tools at all. One student explicitly noted that "teachers and instructors have problems working with digital programs". There is no doubt that distance education will be actively developed. At the same time, the pandemic was a trigger. Teachers must clearly understand that further educational activities involve the development and use of digital platforms and tools in the learning process. It is known that "students are increasingly using tools such as the Massive Open Online Courses (MOOC), Wikipedia, discussion chats, and even social networks. They also use digital laboratories and online simulators. The handwritten outline of lectures is replaced by computer notes, photography or even videotaping of lectures. The professors state with regret that often the listeners, instead of listening to the lecture, find the information in their mobile devices". But it is important to emphasize that modern technologies allow the mobility of students "without leaving home": it is possible to listen to 
a lecture or presentation, which is held in a university, which is situated even on another continent. All university teachers face this challenge, which requires a significant change in pedagogical approaches and a reasonable balance between "live" communication with the teacher and "virtual" learning".

3) Acute dissatisfaction of students with the transfer to a remote format of practical forms of classes. Conducting educational and production practices are an integral part of engineer training. So, the curriculum of students' training of the "Automobile transport" faculty of MADI includes training practice "to get primary professional knowledge and skills, including primary knowledge and skills of research activities", which is carried out at the department "Technologies of construction materials". As it was mentioned above, at the end of the practice a survey of participants was conducted on a sample population (determined by nesting method in six groups with a total number of 86 students). The results of the survey are as follows. The majority of students (79\%) were opposed to conducting this practice in a remote format, and only $8 \%$ rated this format positively, while $13 \%$ of respondents were undecided.

In addition to statistical analysis of the results, students' opinions were also recorded. They generally appreciated the efforts of the practice organizers in this challenging environment. The future motorist expressed the consolidated opinion of the trainees in this way: "I liked very much the lecture on examination of reasons of car parts failure. Because responsible work ... requires a lot of effort, knowledge and practical skills to conduct a quality examination of a vehicle: to identify the real causes of problems in the work of the car ..." Many students thought that the practice was informative: "it was useful to learn that other countries, it turns out, have their own markings (steel grades - author's note). But, here: "it would be good if we could see these very analogous steels and touch them"; "it would be cool to try to make a part with the help of a teacher, maybe even according to your own drawing".

In general, the overwhelming majority of respondents expressed a desire to conduct the practice "live": "inspection report (of a damaged automobile - author's note)) is the most fun and coolest task. It was not very interesting or accurate to do it virtually by photo. It would be much better to do it hands-on and a very useful experience in car inspection". Or such an opinion: "I want to see in real life how the examination is carried out and to study it in more detail".

Students want to have an internship at different enterprises: "I would like to know more professional and real activities, to know, to see and take part in the technical processes and in the work process of the automobile enterprise itself"; "...it would be interesting to see a real enterprise (factory) that manufactures components. It would be just as great to accomplish the task together with the employees of such an enterprise or plant, where they can give an example of the use of a part, its creation, description of the structure"; "Maybe it could be possible to arrange a practical training by some company that specializes in appraising cars and have that dealer allow us to appraise a car by ourselves. The experience would be very useful".

Thus, the survey showed that while passing the internship, future engineers are waiting for the real activity at the enterprise, which allows them to concentrate on obtaining professional skills, which is consistent with the analysis of the needs of modern technical intellectuals in professional development (Makarenko et al., 2018). One of the trainees generalized the problem: "I would like to see how the engineers really work. How to make a map of how to process a part in production, what to take into account 
when creating it, what materials are selected, how are they processed in practice, etc. In general, to incorporate MORE ENGINEERING".

\subsection{Problems of social adaptation related to educational activities}

It follows from the above that modern demands of students require new pedagogical approaches. One of the representatives of the future engineering corps approached the description of the specifics of adaptation to study in the conditions of the pandemic: "This social adaptation ... is characterized by a fourstep model of stages of adaptation. At the initial stage, a teacher may consider distance learning to be ineffective due to his conservative beliefs and years of experience working exclusively directly with students. In the second stage, a teacher understands that there are certain advantages of distance learning, that a teacher has a vision and begins to develop himself or herself to improve the quality of his or her distance learning lessons, to look for new methods of communication and convenient forms of teaching and demonstration of something to students. In the third stage, the instructor recognizes that, with the right approach, both on his/her part and that of the students; distance learning is as good as face-to-face learning. Of course, this is not the case in all areas, but I will repeat that, with the right approach on both sides, many subjects can be taught remotely, providing a level of education as high as that of face-to-face instruction. Proof of the fourth stage of adaptation is the fact that today we see a lot of tutors who teach online, a lot of different online courses in different disciplines and the like".

Communication challenges in adapting to the pandemic are an important factor. 8 students noted that self-isolation, quarantine measures, and distance learning have weakened their communication abilities. Students tend to "miss" the usual direct form of interaction: "It is necessary to get used to the peculiarities of communication through the Internet without face-to-face meetings; "I... am already used to it, and working remotely, but studying at the institute is still more practical and time is distributed more comfortably. I am in my homeland, the city [cut out]. I left for 3 days, and now it's been 2 months". Many people note a change in leisure time. Here there is a contradictory situation: on the one hand - regret about the inability to visit theaters, exhibitions, and on the other - students note new ways to realize their hobbies, to enjoy close contact with relatives.

In the aspect of social adaptation, some students consider adaptation to forced change of place and form of residence as the main factor ( 4 people): namely, leaving home (departure from the usual environment for studies), difficulties with the Internet (as mentioned above), changing environment (friends, acquaintances) and even breaking civil relations with their significant others.

Several students indicated a positive effect of social adaptation in challenging environments: they emphasized that distance learning allowed them to save time (especially on their way to university). In general, it should be recognized that students of the Faculty of Design and Mechanical Engineering were much more active in adapting to academic activities, while the future road engineers considered the problems of social responsibility more important.

Financial difficulties and adaptation in terms of material resources were mentioned by 6 respondents. As a rule, this kind of adaptation manifests itself indirectly for future engineers: through parents, relatives and friends. In principle, for students in general, this type of adaptation is not a direct type of social adaptation, but is mediated, because full employment and financial resources are not the mainstay of their 
student activities. However, economic and financial difficulties have affected them to some extent. A number of students pointed to the difficulty of solving material and financial problems: "Indeed, because of the pandemic, our society has become even more stratified. How could it be otherwise, if there is no subsidy for citizens, which further affects the issue of earning? It is not difficult to understand the situation of those people who have lost their last money for life. These phenomena became the impetus for widespread violation of self-isolation"; "more than once I thought about the fact that many citizens are now forced to spend "piggy bank money" on basic necessities".

Another important aspect of financial difficulties is that students work part-time. Some do so to gain experience, but there is a group of students, including technical students, who are forced to seek forms of income because of their difficult financial situation in the family. How have they adapted to the conditions of the pandemic crisis in this situation? They began to work more "remotely" like the majority of the country's population. Some people were doing better, others - worse. But in general, as a generation, intensively using digital technologies, they saw new opportunities to work remotely using digital applications.

\subsection{Creating social responsibility}

Content analysis showed that social responsibility took second place in students' assessment of social adaptation problems. This problem was mentioned in 14 essays. The address of students to some important aspects of social responsibility during the pandemic can be considered as a positive characteristic of the formation of domestic engineers. It characterizes them as active, not indifferent to processes of personalities, taking place in the Russian society. Among various directions of manifestation of social responsibility the questions of organization of medical aid, system of public health services, the special relation to doctors, hospital employees, which have literally risen on par with the spread of the coronavirus infection, have come to the first place of students. Students wrote quite sincerely that "now people show great confidence in medical workers and that our Government finally paid attention to this area of life, it has gotten better at financing the field it and closely monitors the wellbeing of Russians. Some students have directly faced the pandemic through their relatives and friends: "My sister and her husband work in the hospital, my husband is a surgeon, works and is on duty every day, there is one hospital per region and almost one, everyone is sick. It's just terrible". There were also such essays, which raised questions almost at the state level: "in general, life after quarantine will gradually get back to normal, and this pandemic cannot be called a turning point. However, one can learn from this phenomenon about the priority of financing medicine and science, as well as about "What is the state for us and what its role is".

The second thing that concerns modern future engineers within the framework of social responsibility and forms their personality is their attitude towards other people. It should be noted that social responsibility, special world-view and humanitarian positions in many ways characterized domestic engineers, representatives of technical intelligentsia in different years. This is a kind of social continuity within the professional community. It is no secret that an engineer should see in every technical solution its social content. It is his high mission in society. Without a broad understanding of social problems, humanism, respect for other people, one cannot take place as a professional and high-class specialist. Without these qualities, it will be impossible to develop the economy, to build a new modern industry, to 
solve the issues of technological development. According to the results of the signal study, it can be stated that in the current socio-economic situation, many students are concerned about social responsibility, relationships in society, group, understanding the difficulties for many people. Most are aware of them at the level of wearing masks and personal protective equipment (PPE). For example, respondents said: "I need to go to the store for groceries; I necessarily take a mask and antiseptic with me. I won't go into details about the antiseptic, but I will elaborate on the mask. A mask is the first precaution to protect not myself from others, but others from myself! In my opinion, this idea is imperative, and such a spiteful attitude of people is present, because they simply have not been explained: why to wear a mask"; "The coronavirus pandemic is now raging in our country and all people have to adapt to the quarantine and self-isolation mode. Everyone sits at home and can get out of it only if there is an urgent need. All entertainment facilities and most stores are closed, and you can stay outside only in masks and gloves. And everyone should understand that the lives of others depend on what another person will do". What is interesting, in general, students do not approve of people who do not use PPE: "there are people who wanted to ignore all bans, primary precautions, social distance, etc.", "but there are also countries that have ignored the virus or have not taken the necessary measures, as well as for the lack of social responsibility of people have not reached even the peak of infection and predict terrible results in the next month. From this it can be concluded that the rapidly socially adapted countries are in a better place than those who have ignored or refused to take any precautions". "Only by uniting and observing all the rules and security measures that we are recommended will we be able to go through this together and return to the same rhythm of life again". Ultimately, our future engineers are aware of the degree of responsibility not only for their own health, but for others as well. A representative of the Faculty "KM" formulated this idea as follows: "A deadly virus is spreading in our beloved country, and the most serious and decisive measures have been taken in this regard. This is a process of self-isolation, the closure of most stores except for those with basic necessities, and most importantly - the risk of falling ill. The worst thing is that if the body has a weak immunity, the outcome may even be fatal. Therefore, the process of adaptation in these days has changed the lifestyle of millions of people. Before going out to the street, you need to get a pass, to think about, if it is necessary to go out at all. Should you put on a mask, keep a distance and much more. This situation has made me, an ordinary person, adapt to everything that happens in the most serious way, because health is life".

And finally, the third, but not the last in importance, direction of manifestation of social responsibility, which is supported by students, is volunteer movement. Some students have explicitly mentioned this active way of adapting to the pandemic and have themselves participated in various forms of this movement.

\section{Conclusion}

According to the results of the study, we distributed the adaptation problems faced by students related to the sudden transition to distance learning, in descending order of their references in the essays, and, where possible, compared with data from a mass survey (Aleshkovskiy et al., 2020).

1) The inability to quickly adapt to sudden changes in the forms of learning activity. Our observation coincides with the data of the mass survey (Aleshkovskiy et al., 2020): "only a fifth of the respondents (22.3\%) calmly perceived the need to change the usual form of education. Fear for their education and 
passing the future certification was mentioned by $23.4 \%$ of respondents. $21.0 \%$ felt disillusionment and uncertainty about their involvement in the educational process".

2) Technical problems (quality of connection, lack of necessary equipment). According to the data given in (Aleshkovskiy et al., 2020), 24.4\% of the interrogated named technical problems (Internet speed, quality of communication) and lack of necessary equipment (headphones, microphones, cameras with good resolution) as the main difficulties. At the same time, the respondents were optimistic about saving time for moving around and acquiring new experience.

3) Awareness of the need for social responsibility, which manifested itself in respect for the work of medical staff, in relation to other people, the awareness of the responsibility of the future engineer to society, the need to participate in the volunteer movement.

4) Acceleration of communication problems related to the transformation of personal connections into remote ones. From our point of view, this transformation took place in the era of mobile communications, messengers, etc., and due to the pandemic the importance of correct attitude towards this problem has increased. According to (Aleshkovskiy et al., 2020), the lack of personal communication $(19.2 \%)$ and lack of direct communication with teachers $(18.2 \%)$ were complained about.

5) Financial and domestic problems.

Our work is just one touch to the "portrait" of public opinion based on sociological research on the advantages, disadvantages and prospects of distance education. The results of the content analysis of the opinions of MADI students in general coincide with the results of processing a mass survey of students of different universities. Further analysis of the problems of distance learning is necessary.

\section{References}

Aleshkovskiy, I. A., Gasparishvili, A. T., Krukhmaleva, O. V., Narbut, N. P., \& Savina, N. E. (2020). Russian university students about distance learning: assessments and opportunities. Higher Education in Russia, 10(29), 86-100.

Donskikh, O. A. (2020). The New Normal? Higher Education in Russia, 10(29), 56-64.

Gafurov, I. R., Ibragimov, H. I., Kalimullin, A. M., \& Alishev, T. B. (2020). Transformation of higher education during the pandemic: pain points. Higher Education in Russia, 10(29), 101-112.

Guralnik, D. (2020). Reimagining educational experiences at a critical time. International Journal of Engineering Pedagogy, 3(10).

Makarenko, E., Petrova, L., Solovyev, A., \& Prikhodko, V. (2018). Assessing the needs of technical intelligentsia for professional development. Advances in intelligent systems and computing, 715, 233-238.

Melezhik, K. A., Petrenko, A. D., \& Khrabskova, D. M. (2020). Reflective hyperconnectivity of social networks virtual space as a factor in the design of distant learning environment. Higher Education in Russia, 10(29), 46-55.

Mikhailov, O. V., \& Denisova, Y. V. (2020). Distance learning at Russian universities: "Step forward, two steps back?" Higher Education in Russia, 10(29), 65-76.

Morshchilov, M., Petrova, L., Prikhodko, V., \& Abrakov, S. (2019). Some problems of advancement of modern information technology in the Russian engineering education. Advances in Intelligent Systems and Computing, 917, 636-644. 